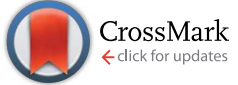

Cite this: RSC Adv., 2016, 6, 49995
Received 22nd February 2016 Accepted 5th May 2016

DOI: $10.1039 / \mathrm{c} 6 \mathrm{ra0} 4665 \mathrm{~g}$

www.rsc.org/advances

\section{Decolorization enhancement by optimizing azo dye loading rate in an anaerobic reactor}

\author{
Min-Hua Cui, $\dagger^{a}$ Dan Cui, $\dagger^{b}$ Bin Liang, ${ }^{b}$ Thangavel Sangeetha, ${ }^{a}$ Ai-Jie Wang ${ }^{\star a b}$ \\ and Hao-Yi Cheng*b
}

An up-flow anaerobic sludge blanket (UASB) reactor was developed to investigate the effect of azo dye loading rate on the decolorization performance and microbial community. The results indicated that the decolorization efficiency decreased from $95.84 \pm 2.60$ to $62.98 \pm 8.66 \%$ with the azo dye loading rate increasing from 100 to $800 \mathrm{~g} \mathrm{~m}^{-3} \mathrm{~d}^{-1}$. The inhibition of the high azo dye loading rate on the microbial activity was reversible. The decolorization efficiency rose with the azo dye loading rate decreasing and recovered to $92.15 \pm 3.86 \%$ at an azo dye loading rate of $600 \mathrm{~g} \mathrm{~m}^{-3} \mathrm{~d}^{-1}$. The results of $16 \mathrm{~S}$ rRNA gene sequencing based on the high-throughput Illumina MiSeq sequencing showed that the microbial diversity of the sludge in UASB was reduced compared to the inoculum. Proteobacteria (40.51\%) and Firmicutes (33.17\%) were enriched. Enterobacter and Enterococcus with relative abundances of $26.99 \%$ and $20.38 \%$ were the most enriched genera, which were also functional for azo dye reduction.

\section{Introduction}

Azo dye, consisting of at least one azo bond $(-\mathrm{N}=\mathrm{N}-)$ and various auxochrome groups (such as $-\mathrm{NO}_{2},-\mathrm{SO}_{3} \mathrm{H},-\mathrm{COOH}$, $-\mathrm{OH}$, halogens, etc.), is one of the most important industrial chemicals and is extensively used in the textile, paper, cosmetic and food industries. ${ }^{1}$ In the printing and dyeing industries, more than half of the consumed dyestuffs are azo dyes. ${ }^{2}$ Approximately $10 \%$ of the produced dyes are unused and are discharged in aqueous effluent. ${ }^{3}$ Colored wastewater discharged without adequate treatment would pose numerous serious environmental problems (e.g. aesthetic problems, deterioration of the water into which it is discharged and light penetration). ${ }^{4}$ It is a pivotal triggering factor for severe aqueous environmental pollution in some Asian countries, especially in China. ${ }^{5}$

Many efforts have been made to efficiently treat azo dye containing wastewaters. ${ }^{6}$ Physical and chemical methods, including oxidation, ${ }^{7}$ adsorption ${ }^{\mathbf{8}, 9}$ and coagulation $^{\mathbf{1 0}}$ are employed to remove dyes successfully. Although the advantages of time saving and excellent removal performance attract lots of research attention, the high cost and excess chemical sludge restrict the wide application of physical and chemical methods. A biological process has been proven to be an efficient solution for azo dye containing wastewater remediation. ${ }^{3}$

${ }^{a}$ State Key Laboratory of Urban Water Resource and Environment, Harbin Institute of Technology, Harbin 150090, PR China.E-mail: waj0578@hit.edu.cn

${ }^{b}$ Key Laboratory of Environmental Biotechnology, Research Center for EcoEnvironmental Sciences, Chinese Academy of Sciences, Beijing 100085, PR China. E-mail: hycheng@rcees.ac.cn

$\dagger$ These authors contributed equally to this work.
Azo dye could be biologically decolorized via azo bond cleavage and supplemented by nitro-reduction and dehalogenation under anaerobic conditions rather than aerobic conditions. ${ }^{\mathbf{1 1}}$ Most azo dyes, such as reactive orange $16,{ }^{12}$ congo red, ${ }^{13}$ acid orange 7 (AO7), and alizarin yellow R (AYR) could be anaerobically degraded. Lots of studies have investigated the feasibility of the anaerobic process for azo dye containing wastewater treatment and have optimized the operational parameters. ${ }^{\mathbf{4} 14}$ However, there are still many challenges that have to be overcome, such as increasing endurable azo dye loading rate, evaluating decolorization performance under fluctuating loading rates, exploring the recovery performance of an anaerobic reactor from inhibiting conditions (high loading rate), and analyzing the functional microbial community structure.

In this study, a cubic up-flow anaerobic sludge blanket reactor (UASB) was developed for azo dye removal. Alizarin yellow R (AYR), as a widely used azo dye, was selected as a model azo dye ${ }^{2,15}$ which has an azo bond and a nitro (auxochrome) group for color generation. The effect of the AYR loading rate on decolorization efficiency, as well as VFA production and chemical oxygen demand (COD) removal efficiency, was comprehensively investigated. The performance of the reactor recovery from the inhibition of high AYR loading rate was evaluated as well. Also, the featured microbial community's shock tolerance of azo dye loading rate (ALR) as well as the functional consortium in the UASB sludge was systematically interpreted. The potential functions of the dominant genera identified from the UASB sludge were compared with the published literature. 


\section{Materials and methods}

\subsection{Reactor configuration}

A liter-scale cuboid up-flow anaerobic sludge blanket (UASB) reactor, made of plexiglass, was designed and used in this study. It had a working volume of $1.5 \mathrm{~L}$ with dimensions of $L 10$ $\times W 5 \times H 30(\mathrm{~cm})$. A water distribution plate with equispaced 1 $\mathrm{mm}$ holes was installed $3 \mathrm{~cm}$ from the bottom. The inlet port and outlet port were placed at the bottom and $30 \mathrm{~cm}$ high on the opposite profiles, respectively. The inoculation sludge was mixed from two sources in a $50: 50$ ratio: (1) anaerobic sludge from a small pilot-scale anaerobic baffled reactor (ABR), which had treated azo dye wastewater for more than 9 months; ${ }^{16}$ (2) anaerobic granular sludge from a brewery wastewater treatment facility. Inoculation sludge was used to fill $25 \mathrm{~cm}$ of the height of the reactor.

\subsection{Chemicals and analytical methods}

AYR was purchased from Shanghai Sangon Biotech Co., Ltd., China (commercial purity grade). Liquid samples taken from the reactor were immediately filtered through a $0.45 \mu \mathrm{m}$ filter (Tianjin Jinteng Experiment Equipment Co., Ltd., China). AYR concentration was quantified using a UV-vis spectrophotometer (UV-1800, Shanghai Meipuda instrument Co., Ltd., China) at a wavelength of $374 \mathrm{~nm}^{2}$. The products of AYR decolorization, $p$ phenylenediamine (PPD) and 5-aminosalicylic acid (5-ASA), were measured using a high performance liquid chromatograph (HPLC, e2695, Waters Co., U.S.) equipped with a C18 column (5 $\mathrm{m}$; $4.6 \mathrm{~mm} \times 150 \mathrm{~mm}$, Symmetry, Waters Co., Ltd., U.S.) and a UV detector (model 2489, Waters Co., U.S.) at a wavelength of $288 \mathrm{~nm}$. The mobile phase was a methanol solution and a $0.03 \%$ acetic acid solution with a ratio of $1: 9$ (vol/vol) at a flow rate of $1 \mathrm{~mL} \mathrm{~min}^{-1}$. Volatile fatty acids (VFAs) were measured using a gas chromatograph (GC, 6890N, Agilent, Inc., U.S.) equipped with a flame ionization detector (FID) with oven and injector temperatures of $60^{\circ} \mathrm{C}$ and $250{ }^{\circ} \mathrm{C}$ respectively, a Stabilwax-DA column (30 $\mathrm{m} \times 0.32 \mathrm{~mm} \times 0.5 \mathrm{~mm})$, and $\mathrm{He}$ carrier gas and $\mathrm{N}_{2}$ makeup gas. COD was determined using the dichromate method.

\subsection{Operational conditions}

The influent consisted of AYR (50-200 $\left.\mathrm{mg} \mathrm{L}^{-1}\right)$, glucose $(500 \mathrm{mg}$ $\left.\mathrm{L}^{-1}\right)$ as a co-substrate, $50 \mathrm{mM}$ phosphate buffer solution, $\mathrm{KCl}$ $\left(0.13 \mathrm{~g} \mathrm{~L}^{-1}\right), \mathrm{NH}_{4} \mathrm{Cl}\left(0.31 \mathrm{~g} \mathrm{~L}^{-1}\right)$, trace element solution $(1 \mathrm{~mL}$ $\left.\mathrm{L}^{-1}\right)$ and a vitamin solution $\left(1 \mathrm{~mL} \mathrm{~L}^{-1}\right) .{ }^{17}$ The AYR loading rate (ALR, varying in the range of 100 to $800 \mathrm{~g} \mathrm{~m}^{-3} \mathrm{~d}^{-1}$ ) was regulated by changing the HRT and influent AYR concentration. All of the experiments mentioned above were carried out at ambient temperature $\left(25 \pm 2{ }^{\circ} \mathrm{C}\right)$.

The experiment was conducted in three stages as shown in Table 1. At stage I, AYR removal performance in UASB was examined, with the ALR gradually rising from 100 to $800 \mathrm{~g} \mathrm{~m}^{-3}$ $\mathrm{d}^{-1}$ by increasing the influent AYR concentration from 50 to 200 $\mathrm{mg} \mathrm{L}^{-1}$ and reducing the HRT from 12 to $6 \mathrm{~h}$. At stage II, the ALR was gradually decreased from 800 to $100 \mathrm{~g} \mathrm{~m}^{-3} \mathrm{~d}^{-1}$ to reduce the impeding effect of AYR on the anaerobic microorganisms.
Table 1 Operational conditions of UASB

\begin{tabular}{lllrl}
\hline Stage & Time $(\mathrm{d})$ & $\begin{array}{l}\text { AYR concentration } \\
\left(\mathrm{mg} \mathrm{L}^{-1}\right)\end{array}$ & $\begin{array}{l}\text { HRT } \\
(\mathrm{h})\end{array}$ & $\begin{array}{l}\text { AYR loading rate } \\
\left(\mathrm{g} \mathrm{m}^{-3} \mathrm{~d}^{-1}\right)\end{array}$ \\
\hline I & $1-50$ & $50-200$ & 12 & $100-400$ \\
& $51-60$ & 200 & 8 & 600 \\
& $61-85$ & 200 & 6 & 800 \\
II & $86-96$ & 200 & 8 & 600 \\
& $97-110$ & 200 & 12 & 400 \\
& $111-122$ & 100 & 12 & 200 \\
& $123-144$ & 50 & 12 & 100 \\
III & $145-152$ & 100 & 12 & 200 \\
& $153-166$ & 200 & 12 & 400 \\
& $167-173$ & 200 & 8 & 600 \\
& $174-184$ & 200 & 6 & 800
\end{tabular}

At stage III, the ALR was gradually increased to $800 \mathrm{~g} \mathrm{~m}^{-3} \mathrm{~d}^{-1}$ again to investigate the recovery performance of UASB.

\subsection{Sampling and DNA extraction}

Sludge was extracted from three different positions of the reactor using a sterile injector and mixed as one sample. The biomass was centrifuged at $13000 \mathrm{rpm}$ for $10 \mathrm{~min}$ and the supernatant was removed. This was repeated twice to sufficiently centrifuge the biomass for a further DNA extraction process. The collected biomass was stored in $2 \mathrm{~mL}$ sterile centrifuge tubes at $-70{ }^{\circ} \mathrm{C}$ before DNA extraction. DNA extraction and 16S rRNA gene based Illumina MiSeq sequencing were carried out at Shanghai Sangon Biotech Co., Ltd.

\subsection{High-throughput 16S rRNA gene Illumina MiSeq sequencing}

Amplicon libraries were constructed using Illumina Miseq 2000 using bacterial universal primers $341 \mathrm{~F}$ (5'-CCTACACGACGCTCTTCCGATCTN-3') and 805 R (5'-GACTGGAGTTCCTTGGCACCCGAGAATTCCA-3'). Both forward and reverse primers were added with a barcode. PCR amplification, PCR product purification and quantification, sequencing using the Illumina MiSeq platform at Shanghai Sangon Biotech Co., Ltd. and data analysis has been described elsewhere. ${ }^{18}$

\section{Results and discussion}

\subsection{Decolorization performance}

The reactor was started up with HRT of $12 \mathrm{~h}$ and influent AYR concentration of $50 \mathrm{mg} \mathrm{L}^{-1}$ which gave an ALR of $100 \mathrm{~g} \mathrm{~m}^{-3} \mathrm{~d}^{-1}$ (Fig. 1). In the first 50 days, AYR removal efficiency consistently increased to over 95\% and kept stable when the ALR rose from 100 to $400 \mathrm{~g} \mathrm{~m}^{-3} \mathrm{~d}^{-1}$. Increasing the AYR concentration from 50 to $200 \mathrm{mg} \mathrm{L}^{-1}$ and reducing HRT from 12 to $8 \mathrm{~h}$ did not affect the decolorization efficiency ( $95.84 \pm 2.60 \%$ ) obviously. When the HRT was further shortened to $6 \mathrm{~h}$, the AYR removal efficiency sharply dropped to $62.98 \pm 8.66 \%$ with a lower decolorization rate compared to that of the HRT of $8 \mathrm{~h}$. This implied that a higher ALR ( $\left.800 \mathrm{~g} \mathrm{~m}^{-3} \mathrm{~d}^{-1}\right)$ exhibited an inhibitory effect on the anaerobic microbial metabolic activity. After that, at 


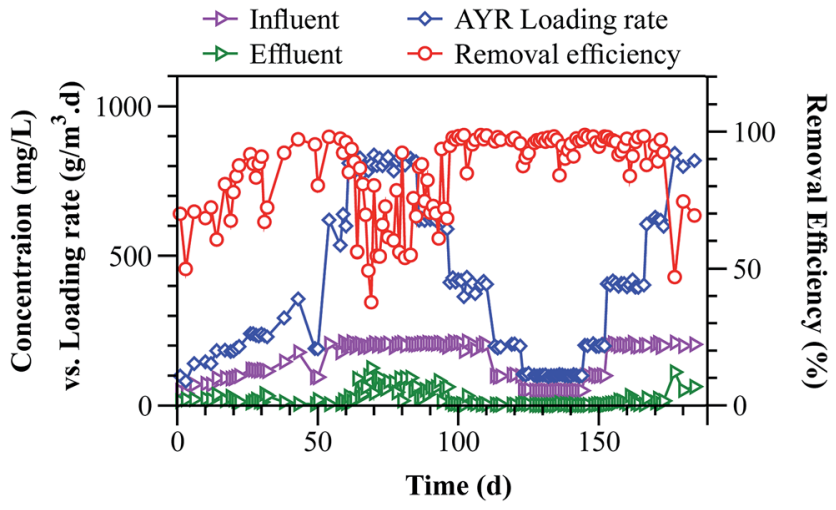

Fig. 1 AYR concentration in influent and effluent, the corresponding removal efficiency and AYR loading rates (ALRS).

stage II, the ALR was gradually reduced from 800 to $100 \mathrm{~g} \mathrm{~m}^{-3}$ $\mathrm{d}^{-1}$ to probe the recovery performance of UASB. The AYR removal efficiency rose up to $76.24 \pm 9.98 \%$ when the HRT was increased to $8 \mathrm{~h}$ (day 86-96) with an ALR of $600 \mathrm{~g} \mathrm{~m}^{-3} \mathrm{~d}^{-1}$. It further increased to $95.32 \pm 3.59 \%$ with the ALR decreasing to $100 \mathrm{~g} \mathrm{~m}^{-3} \mathrm{~d}^{-1}$. These results suggested that UASB could be well released from the inhibition of a high ALR and recover its previous performance. Some published studies have reported that the anaerobic bioreactors can recover from shock loading. ${ }^{19-21}$ Kumar et $a l .{ }^{21}$ implied that an anaerobic hybrid reactor was capable of good and fast recovery after a shock loading and proved that the microorganism could survive the shock loading. At stage III, when the ALR increased to $600 \mathrm{~g} \mathrm{~m}^{-3}$ $\mathrm{d}^{-1}$ with an HRT of $8 \mathrm{~h}$ again, the decolorization efficiency slightly dropped to $92.15 \pm 3.86 \%$. It further reduced to $63.50 \pm$ $14.58 \%$ when the ALR reached the highest level of $800 \mathrm{~g} \mathrm{~m}^{-3}$ $\mathrm{d}^{-1}$. This implied that the endurable ALR of UASB was as high as $600 \mathrm{~g} \mathrm{~m}^{-3} \mathrm{~d}^{-1}$. Although the anaerobic decolorization of AYR was suppressed at a higher loading rate (etc. $800 \mathrm{~g} \mathrm{~m}^{-3} \mathrm{~d}^{-1}$ ), it could recover when the ALR was once again down to a lower level. This clearly indicated that the inhibition of high ALR on the anaerobic functional consortia was reversible.

The reduction products of AYR were detected as being PPD and 5-ASA similar to the previous studies.,22 ${ }^{2,22}$ The reduction of one mole of AYR can produce one mole PPD and one mole 5ASA, theoretically. Here the recovery efficiency is defined as the ratio of the measured value and theoretical value. The average recovery efficiency was $92.83 \%$, which confirmed that the decolorization was due to the reduction of AYR. PPD steadily accumulated in the effluent due to its non-biodegradable nature. The 5-ASA accumulation was much lower than PPD with an average recovery efficiency of $67.24 \%$, because it could be mineralized by functional anaerobes under anaerobic conditions. ${ }^{23}$

\subsection{VFA production and COD removal}

VFAs in the effluent were fermented from glucose. The variation of VFAs is presented in Fig. 2A. Six kinds of VFAs were identified with acetate acid (HAc) and propionic acid (HPr) as the major components. The other VFAs such as iso-butyric acid (0.22-

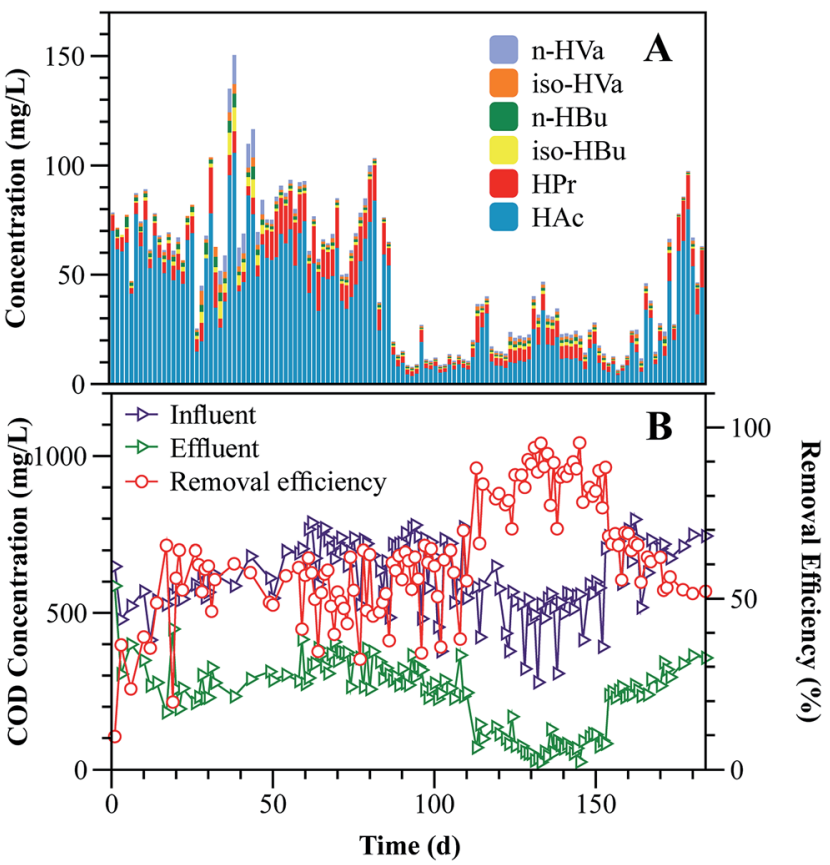

Fig. 2 Variation of organic content. (A) Volatile fatty acid (VFA) variation; (B) COD variation.

$\left.10.76 \mathrm{mg} \mathrm{L}^{-1}\right), n$-butyric acid (0.25-6.29 $\left.\mathrm{mg} \mathrm{L}^{-1}\right)$, iso-valeric acid (0.35-6.42 $\left.\mathrm{mg} \mathrm{L}^{-1}\right)$ and $n$-valeric acid (0.24-13.27 $\left.\mathrm{mg} \mathrm{L}^{-1}\right)$ were negligible. Before day 97 (ALR first reached $800 \mathrm{~g} \mathrm{~m}^{-3} \mathrm{~d}^{-1}$ and then decreased to $600 \mathrm{~g} \mathrm{~m}^{-3} \mathrm{~d}^{-1}$ ), relatively more VFAs accumulated in the effluent and the total VFA concentrations varied from 44.90-150.44 $\mathrm{mg} \mathrm{L}^{-1}$ (Fig. 2A). From day 97 to 166 (ALR varied between 100 and $400 \mathrm{~g} \mathrm{~m}^{-3} \mathrm{~d}^{-1}$ ), the average VFA concentration significantly dropped to $20.51 \mathrm{mg} \mathrm{L}^{-1}$. Then, it increased sharply with the increasing ALR from day 167 (ALR increased to 600 to $800 \mathrm{~g} \mathrm{~m}^{-3} \mathrm{~d}^{-1}$ ). At a lower ALR, anaerobic microorganisms exhibited high VFA consumption efficiency resulting in a low VFA accumulation in the effluent. At a higher $\operatorname{ALR}\left(800 \mathrm{~g} \mathrm{~m}^{-3} \mathrm{~d}^{-1}\right.$ ), the microorganisms were also suppressed leading to a high effluent VFA concentration.

In addition to decolorization, COD removal was also an important index for evaluating the performance of the bioreactor. The COD concentration variation is presented in Fig. 2B. The influent COD was proportional to the sum of the influent AYR and glucose. COD removal efficiencies showed an increasing trend up to $50 \%$ until day 20 , which indicated that the anaerobic microorganisms were well acclimatized. From day 21 to 110, an average of $53.78 \%$ COD removal efficiency was achieved. With the ALR decreasing to $200 \mathrm{~g} \mathrm{~m}^{-3} \mathrm{~d}^{-1}$ from day 111 , the COD removal efficiency was maintained at around $78.79 \%$. Effective organic matter removal was attributed to the readily biodegradable co-substrates (glucose) used in this study. When the ALR was increased from 600 to $800 \mathrm{~g} \mathrm{~m}^{-3} \mathrm{~d}^{-1}$ in the last 18 days, the COD removal efficiency dropped to $54.31 \%$. These results indicated that the UASB achieved a high COD removal efficiency when the ALR was lower than $400 \mathrm{~g} \mathrm{~m}^{-3} \mathrm{~d}^{-1}$ and it decreased approximately a quarter when the ALR was further increased to $800 \mathrm{~g} \mathrm{~m}^{-3} \mathrm{~d}^{-1}$. 


\subsection{Overall microbial community structure}

In order to understand which microbial communities were featured in the phylogenetic diversities of the functional communities in both the inoculum and the UASB sludge sample, the trimmed sequences were grouped into operational taxonomic units (OTUs) using a 97\% identity threshold. As shown in Fig. 3, the OTUs (at a 3\% distance) were 1998 in the inoculum and 1614 for the sample in UASB, which indicated that long term operation reduced the functional community diversity and this was also confirmed by the rarefaction curves. The richness estimator Chao 1 for both samples showed the same trend (4040.90 for inoculum and 3385.18 for UASB sample). The Shannon diversity index provided not only the species richness but also the abundance of each species and distribution of the microbial community. ${ }^{24}$ When the sequencing depth of each sample was $>3000$, the Shannon diversities of the two samples did not increase continuously. This indicated that over 17000 high-quality sequences obtained by Illumina MiSeq sequencing in this study were subjected to total characterization of the targeted microbial communities. The inoculum (5.64) presented a significantly higher Shannon diversity than the UASB sample (4.30). All of those estimators revealed a higher microbial biodiversity in the inoculum than in the UASB sample.

\subsection{Phylum and class level microbial community structure}

A total of 31 phyla were identified including 28 in the inoculum and 24 in the UASB sample (Fig. 4A). Proteobacteria dominated both of the microbial communities and the relative abundance slightly increased from $38.17 \%$ in the inoculum to $40.51 \%$ in the UASB sample. Firmicutes were found to be significantly enriched in the UASB sample $(33.17 \%)$ versus the inoculum (11.91\%). The increase abundance implied that Firmicutes could be the potential phylum involved in AYR decolorization. The relative abundance of the second dominating phylum Bacteroidetes obviously decreased from $26.35 \%$ in the inoculum to $8.87 \%$ in the UASB sample after a long time of operation. The relative abundances of Chloroflexi and Thermotogae decreased from $6.25 \%$ and $1.90 \%$ in the inoculum to $1.95 \%$ and

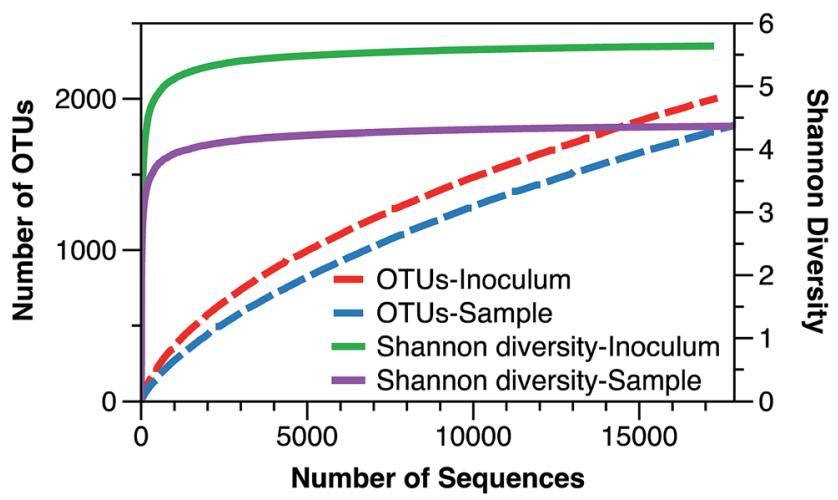

Fig. 3 Rarefaction curves and Shannon diversities of the inoculum and UASB sample.

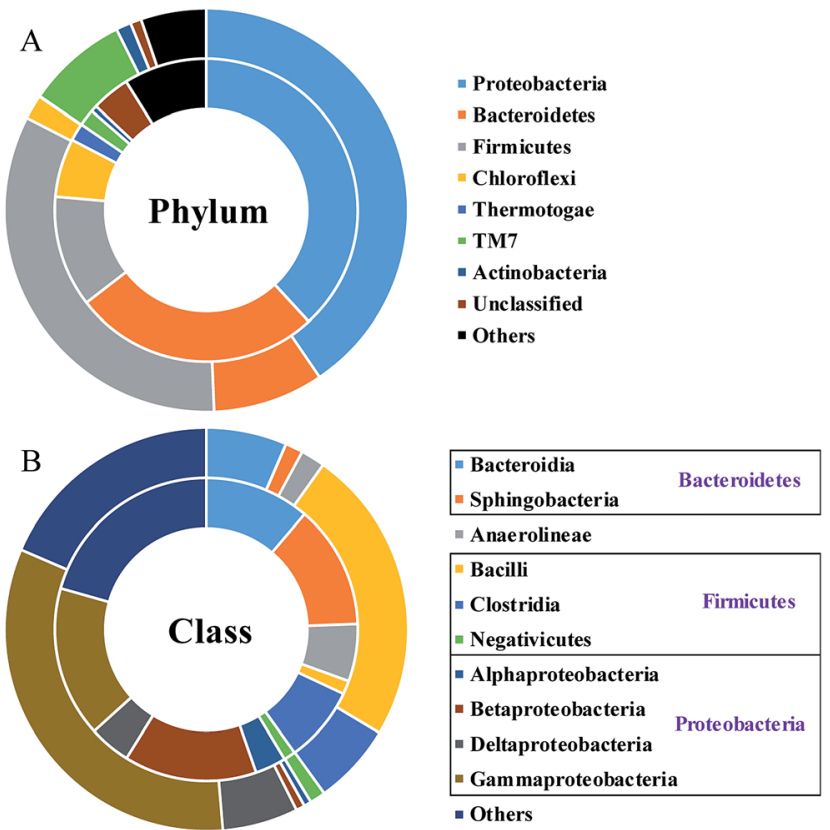

Fig. 4 Taxonomic classification of microbial communities at phylum (A) and class (B) levels. The inner circle represents the inoculum and the outer circle represents the UASB sample.

$0.04 \%$ in the UASB sample, respectively. The other two phyla, TM7 and Actinobacteria were enriched in the UASB sample with relative abundances of $8.12 \%$ and $1.20 \%$, respectively. Their relative abundances in the inoculum and sample were only $1.77 \%$ and $0.68 \%$ respectively.

At the class level, Bacilli were significantly enriched in the UASB sample with relative abundances of $23.75 \%$ and $1.45 \%$ in the inoculum as shown in Fig. 4B. The remarkable increase of Bacilli was in accordance with the rise of Firmicutes. The relative abundances of the other two major classes, Clostridia and Negativicutes, were generally steady. The decrease of Bacteroidia and Sphingobacteria contributed to the decreasing abundance of the phylum Bacteroidetes. Although the relative abundance of the Proteobacteria was not significantly changed, the classes belonging to it changed. Alphaproteobacteria and Betaproteobacteria significantly decreased from $3.30 \%$ and $14.18 \%$ to $0.59 \%$ and $0.71 \%$, respectively. Deltaproteobacteria slightly increased to $6.06 \%$ in the sample against $4.44 \%$ in the inoculum. The relative abundance of Gammaproteobacteria increased from $16.10 \%$ to $32.78 \%$ and this was the major contributor to the increase of the phylum Proteobacteria.

\subsection{Potential function of dominant genera}

In total 367 and 207 genera were identified from the inoculum and UASB samples respectively and there were 32 genera with a relative abundance of higher than $1 \%$. As shown in Table 2 , the dominant genera in the inoculum and UASB sample were obviously altered. Among the identified genera in the inoculum, Pandoraea (5.49\%), Comamonas (3.81\%) and Delftia (1.70\%) were reported to possess the abilities of azo dye decolorization and nitro-compound reduction. ${ }^{25-28}$ Most of the genera from the 
Table 2 Phylogenetic classification of the 16S rRNA gene sequences (relative abundance $>1 \%$ at genus levels) in the inoculum and sample

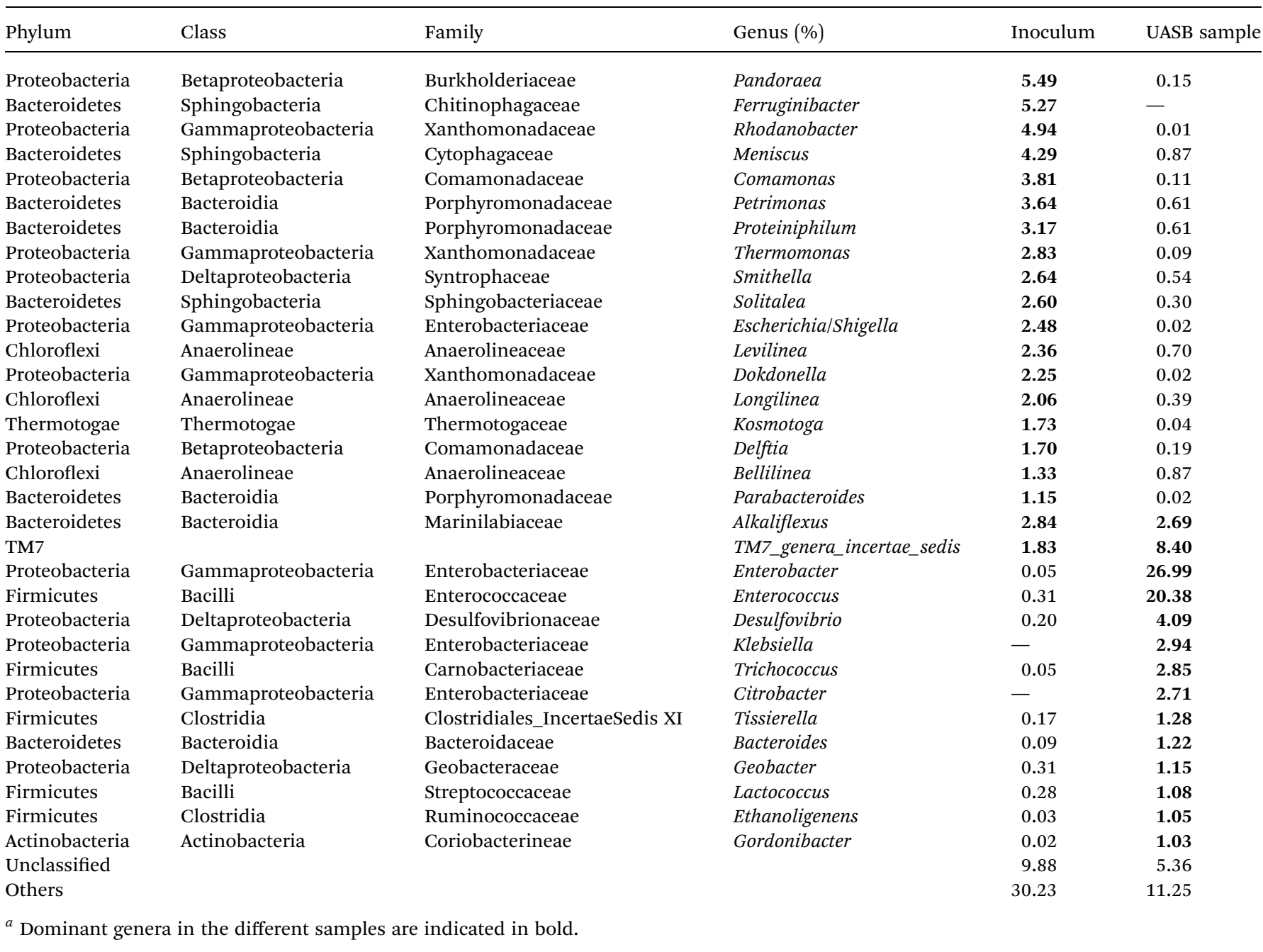

inoculum were not reported to reduce azo dye and nitro directly. All of the dominant genera in the inoculum were at the same order of magnitude. However, two genera, namely Enterobacter (26.99\%) and Enterococcus (20.38\%), were significantly enriched in the UASB sample. Their relative abundances accounted for nearly half of the total sequences, which contributed to the enrichment of Gammaproteobacteria and Bacilli, respectively. Enterobacter and Enterococcus have been widely reported as functional genera for azo dye and nitrocompound reduction. ${ }^{1,29-31}$ Desulfovibrio (4.09\%) was also reported to be involved in azo dye reduction. ${ }^{32}$ Klebsiella and Citrobacter identified in the sample (relative abundances of $2.94 \%$ and $2.71 \%$, respectively) but not in the inoculum were capable of reducing azo dye and amino aromatic acids. ${ }^{33,34}$ Lactococcus also exhibited azo dye decolorization ${ }^{35}$ and nitrocompound biotransformation properties. ${ }^{36}$ Alkaliflexus with a similar relative abundance of $2.84 \%$ in the inoculum and $2.69 \%$ in UASB sample, was associated with a carbohydratefermenting ability to produce propionate..$^{37}$ These results showed that long-term operation could enrich the functional consortia and enhance the microbial community to better adapt to the environment.
Archaea were identified in both the inoculum and UASB sample, with a $3.48 \%$ and $3.37 \%$ presence in the total sequences. The low relative abundances in the UASB sample implied that most of the co-substrates were consumed for AYR bio-reduction instead of getting converted into biogas. Methanosaeta was the majority member in both communities, which accounted for $78.00 \%$ of the archaea consortium in the inoculum and was further enriched to $93.19 \%$ over time. Methanosaeta was dominant in the methanogenic population of an anaerobic baffled reactor during treatment of industrial dye wastewaters ${ }^{38}$ and has also been one of the dominant archaea in the nitro-reduction of nitro aromatics, ${ }^{39}$ which was consistent with our study because the AYR tested here contained both an azo bond and a nitro group. The high ratio of Methanosaeta in the microbial community likely accounted for a better performance of AYR decolorization in the UASB.

\subsection{Comparison of dominant genera with anaerobic biological systems}

The decolorization and nitro reduction capabilities of Enterobacter, Enterococcus and Desulfovibrio were proven with pure 
culture validation tests by various literature as presented above. Analyzing microbial communities from dye treatment facilities operated with mixed cultures and fluctuating conditions could be more reasonable to explain the potential functions of the dominant genera. Table 3 showed the dominant members compared with anaerobic systems reported previously. Most of the identified genera belonged to the phylum of Proteobacteria, such as Pseudomonas, Klebsiella, Enterobacter, Desulfomicrobium, Desulfovibrio, Novispirillum and Rhodobacter, and others were Bacteroidetes (Bacteroides) and Firmicutes (Enterococcus). Although the genera of Klebsiella, Bacteroides, Desulfomicrobium and Desulfovibrio were not the most dominant members in this study, they were significantly enriched compared to the relative abundances in the inoculum as shown in Table 3.

\section{Conclusions}

UASB was efficient for azo dye containing wastewater treatment. The decolorization efficiency was $95.84 \pm 2.60 \%$ with a loading rate of $600 \mathrm{~g}$-AYR $\mathrm{m}^{-3} \mathrm{~d}^{-1}$. A higher loading rate $\left(800 \mathrm{~g}\right.$-AYR m $\mathrm{m}^{-3}$ $\mathrm{d}^{-1}$ ) caused a reversible inhibition of the anaerobic consortia leading to a dramatic drop in decolorization efficiency. The inhibition could be reversed when the azo dye loading rate was reduced again. In terms of the microbial community structure, the phyla Proteobacteria dominated the UASB with a relative abundance of $40.51 \%$, followed by the class of Gammaproteobacteria with a highest relative abundance of $32.78 \%$. The azo dye reduction functional genera, Enterobacter (26.99\%) and Enterococcus (20.38\%) were significantly enriched.

\section{Acknowledgements}

This research was supported by the National Nature Science Foundation for Distinguished Young Scholars (Grant No. 51225802), the National Nature Science Foundation of China (Grand No. 51508551), the China Postdoctoral Science Foundation (Grand No. 2015M580140), the Ministry of Environmental Protection of the People's Republic of China (Major Science and Technology Program for Water Pollution Control and Treatment) (No. 2014ZX07204-005), the "Hundred Talents Program" of the Chinese Academy of Sciences (Grant No. 29BR2013001) and the Jiangsu Key Laboratory of Chemical Pollution Control and Resources Reuse in NJUST (Grant No. 30920140122008).

\section{References}

1 A. Moutaouakkil, Y. Zeroual, F. Z. Dzayri, M. Talbi, K. Lee and M. Blaghen, Curr. Microbiol., 2004, 48, 124-129.

2 D. Cui, Y. Q. Guo, H. Y. Cheng, B. Liang, F. Y. Kong, H. S. Lee and A. J. Wang, J. Hazard. Mater., 2012, 239-240, 257-264.

3 C. Pearce, Dyes Pigm., 2003, 58, 179-196.

4 Z. B. Chen, M. H. Cui, N. Q. Ren, Z. Q. Chen, H. C. Wang and S. K. Nie, Bioresour. Technol., 2011, 102, 8839-8847.

5 S. Sandhya and K. Swaminathan, Chem. Eng. J., 2006, 122, 87-92. 
6 B. Liang, Q. Yao, H. Cheng, S. Gao, F. Kong, D. Cui, Y. Guo, N. Ren, D. J. Lee and A. Wang, Environ. Sci. Pollut. Res. Int., 2012, 19, 1385-1391.

7 M. Qiu and C. Huang, Desalin. Water Treat., 2012, 24, 273277.

8 A. Mittal, V. K. Gupta, A. Malviya and J. Mittal, J. Hazard. Mater., 2008, 151, 821-832.

9 A. Mittal, V. Thakur, J. Mittal and H. Vardhan, Desalin. Water Treat., 2013, 52, 227-237.

10 J. Beltrán-Heredia and J. Sánchez Martín, Color. Technol., 2008, 124, 310-317.

11 M. Jonstrup, N. Kumar, M. Murto and B. Mattiasson, Desalination, 2011, 280, 339-346.

12 M. Z. Khan, S. Singh, T. R. Sreekrishnan and S. Z. Ahammad, RSC Adv., 2014, 4, 46851-46859.

13 M. Isik and D. T. Sponza, Bioresour. Technol., 2005, 96, 633643.

14 D.-X. Hu, M.-H. Cui, Z.-B. Chen, Y. Tian, Y.-B. Cui, N.-Q. Ren, C.-Q. Ran and H.-J. Sun, Desalin. Water Treat., 2013, 52, 5553-5562.

15 D. Cui, Y.-Q. Guo, H.-S. Lee, H.-Y. Cheng, B. Liang, F.-Y. Kong, Y.-Z. Wang, L.-P. Huang, M.-Y. Xu and A.-J. Wang, Chem. Eng. J., 2014, 243, 355-363.

16 D. Cui, Y. Q. Guo, H. S. Lee, W. M. Wu, B. Liang, A. J. Wang and H. Y. Cheng, Bioresour. Technol., 2014, 163, 254-261.

17 A. J. Wang, H. Y. Cheng, B. Liang, N. Q. Ren, D. Cui, N. Lin, B. H. Kim and K. Rabaey, Environ. Sci. Technol., 2011, 45, 10186-10193.

18 C. Yang, W. Liu, Z. He, S. Thangavel, L. Wang, A. Zhou and A. Wang, Bioresour. Technol., 2014, 175, 509-516.

19 A. Gangagni Rao, G. Venkata Naidu, K. Krishna Prasad, N. Chandrasekhar Rao, S. Venkata Mohan, A. Jetty and P. N. Sarma, Bioresour. Technol., 2005, 96, 87-93.

20 D. Sreekanth, D. Sivaramakrishna, V. Himabindu and Y. Anjaneyulu, Bioresour. Technol., 2009, 100, 2534-2539.

21 A. Kumar, A. K. Yadav, T. R. Sreekrishnan, S. Satya and C. P. Kaushik, Bioresour. Technol., 2008, 99, 3123-3129.

22 B. Donlon, E. RazoFlores, M. Luijten, H. Swarts, G. Lettinga and J. Field, Appl. Microbiol. Biotechnol., 1997, 47, 83-90.

23 E. Razo Flores, M. Luijten, B. A. Donlon, G. Lettinga and J. A. Field, Environ. Sci. Technol., 1997, 31, 2098-2103.
24 L. Lu, D. Xing and N. Ren, Water Res., 2012, 46, 2425-2434. 25 C. Y. Chen, J. T. Kuo, C. Y. Cheng, Y. T. Huang, I. H. Ho and Y. C. Chung, J. Hazard. Mater., 2009, 172, 1439-1445.

26 U. U. Jadhav, V. V. Dawkar, G. S. Ghodake and S. P. Govindwar, J. Hazard. Mater., 2008, 158, 507-516.

27 S. F. Nishino and J. C. Spain, Appl. Environ. Microbiol., 1995, 61, 2308-2313.

28 Y. Stolze, F. Eikmeyer, D. Wibberg, G. Brandis, C. Karsten, I. Krahn, S. Schneiker-Bekel, P. Viehover, A. Barsch, M. Keck, E. M. Top, K. Niehaus and A. Schluter, Microbiology, 2012, 158, 2060-2072.

29 F. Rafii, R. Wynne, T. M. Heinze and D. D. Paine, FEMS Microbiol. Lett., 2003, 225, 195-200.

30 A. Bafana, T. Chakrabarti, P. Muthal and G. Kanade, Ecotoxicol. Environ. Saf., 2009, 72, 960-964.

31 W. Handayani, V. I. Meitiniarti and K. H. Timotius, World J. Microbiol. Biotechnol., 2007, 23, 1239-1244.

32 E. S. Yoo, J. Libra and U. Wiesmann, Water Sci. Technol., 2000, 41, 15-22.

33 P. K. Wong and P. Y. Yuen, Water Res., 1996, 30, 1736-1744. 34 O. Savelieva, I. Kotova, W. Roelofsen, A. J. M. Stams and A. Netrusov, Arch. Microbiol., 2004, 181, 163-170.

35 S. J. You and J. Y. Teng, J. Taiwan Inst. Chem. Eng., 2009, 40, 500-504.

36 K. H. Shin, Y. Lim, J. H. Ahn, J. Khil, C. J. Cha and H. G. Hur, Chemosphere, 2005, 61, 30-39.

37 T. N. Zhilina, R. Appel, C. Probian, E. L. Brossa, J. Harder, F. Widdel and G. A. Zavarzin, Arch. Microbiol., 2004, 182, 244-253.

38 J. J. Plumb, J. Bell and D. C. Stuckey, Appl. Environ. Microbiol., 2001, 67, 3226-3235.

39 Z. Zhao, Y. Feng, H. Feng, A. Ghulam, Y. Su and D. Shen, J. Environ. Sci. Health, Part A: Toxic/Hazard. Subst. Environ. Eng., 2014, 49, 1187-1197.

40 A. Bafana, T. Chakrabarti, K. Krishnamurthi and S. S. Devi, Bioresour. Technol., 2008, 99, 5094-5098.

41 H. Lu, J. Wang, S. Lu, Y. Wang, G. Liu, J. Zhou and Z. Quan, Appl. Biochem. Biotechnol., 2015, 175, 2574-2588.

42 L. L. Zhang, Y. H. Sun, D. L. Guo, Z. R. Wu and D. M. Jiang, Afr. J. Microbiol. Res., 2012, 6(35), 6444-6453. 